\title{
Impella CP in cardiogenic shock due to acute myocardial infarction: From primary angioplasty to LIMA-LAD grafting
}

\author{
Jerzy Sacha ${ }^{1,2}$, Jacek Kaperczak ${ }^{3}$, Witold Gwóźdźz , Maciej Marszalski ${ }^{4}$, Maciej Molsa ${ }^{4}$, Marek Cisowski \\ 'Department of Cardiology, University Hospital, Institute of Medical Sciences, University of Opole, Opole, Poland \\ ${ }^{2}$ Faculty of Physical Education and Physiotherapy, Opole University of Technology, Opole, Poland \\ ${ }^{3}$ Department of Cardiac Surgery, University Hospital, Institute of Medical Sciences, University of Opole, Opole, Poland \\ ${ }^{4}$ Department of Anesthesiology, Intensive Care and Regional ECMO Center, Institute of Medical Sciences, University of Opole, Opole, Poland
}

\author{
Correspondence to: \\ Jerzy Sacha, MD, PhD, \\ Department of Cardiology, \\ University Hospital, \\ Institute of Medical Sciences, \\ University of Opole, \\ Witosa 26, 45-401 Opole, Poland, \\ phone: +48 774520660 , \\ e-mail: sacha@op.pl \\ Copyright by the Author(s), 2021 \\ Kardiol Pol. 2021; \\ 79 (12): 1389-1390; \\ DOI: 10.33963/KP.a2021.0152 \\ Received: \\ August 7, 2021 \\ Revision accepted: \\ October 29, 2021 \\ Published online: \\ November 3, 2021
}

Percutaneously implanted mechanical circulatory support devices constitute a significant advance in the treatment of cardiogenic shock, especially in acute myocardial infarction (MI), where they support myocardial revascularization and recovery [1].

A 66-year-old diabetic woman, after 4 anterior Mls, was admitted with cardiogenic shock due to another anterior MI. Three months earlier, during the last MI, the patient underwent the percutaneous coronary intervention of the left anterior descending artery (LAD) with lithotripsy (shockwave balloon $3.5 \mathrm{~mm}, 80$ applications) and the high-pressure balloon angioplasty (OPN NC balloon [SIS Medical AG, Frauenfeld, Swiss], 40 atm) of the calcified lesion covered with previously implanted 2 under-expanded stents. The intervention was ineffective since the final minimal stent area was $2.7 \mathrm{~mm}^{2}$ (Figure 1A); however, the patient refused coronary artery bypass grafting (CABG) at that time.

On the present admission, the patient was in shock with pulmonary edema: the blood pressure was $100 / 60 \mathrm{~mm} \mathrm{Hg}$ on noradrenaline infusion, the lactate level was $3.54 \mathrm{mmol}$ (cardiogenic shock stage $\mathrm{C}$ in the Society for Cardiovascular Angiography and Interventions [SCAI] classification) [2], and the glycemia level was $439 \mathrm{mg} / \mathrm{dl}$. On echocardiography, the ejection fraction was $30 \%$ with akinesia of all apical segments and the mid-septal segment. In the emergency room, the patient was intubated and transferred to the catheterization laboratory.

Coronary angiography revealed stent thrombosis in the proximal and mid LAD (Figure 1B), chronic total occlusion of the distal circumflex artery, and the stenosed hypoplastic right coronary artery. After the Impella $\mathrm{CP}^{\circ}$ (Abiomed, Danvers, MA, USA) insertion (via the left femoral access), the balloon angioplasty of the LAD was performed, restoring a normal blood flow (Figure 1C). Since the target lesion could not be dilated even with lithotripsy, the patient was scheduled for CABG after clinical stabilization. On the Impella support, the arterial pressure was $110 / 105 / 107 \mathrm{~mm} \mathrm{Hg}$, and the pulmonary artery catheterization revealed: right atrial pressure $5 / 6 / 5 \mathrm{~mm} \mathrm{Hg}$, right ventricular pressure $21 / 1 / 5 \mathrm{~mm} \mathrm{Hg}$, pulmonary artery pressure 21/13/16 mm Hg, pulmonary capillary wedge pressure 6/8/6 mm Hg, cardiac output (CO) $2.03 \mathrm{l} / \mathrm{min}$, cardiac power output (CPO) $0.48 \mathrm{~W}$, pulmonary artery pulsatility index 1.6 . However, if the Impella was stopped, the cardiac output parameters immediately dropped: $\mathrm{CO}$, $1.53 \mathrm{l} / \mathrm{min}, \mathrm{CPO}, 0.36 \mathrm{~W}$.

Due to severe heart failure, decompensated diabetes mellitus, deep acidosis, polyuria, and respiratory failure, the patient required prolonged treatment in the intensive care unit. During that time, the patient was dependent on the Impella support; however, the noradrenaline infusion was gradually reduced, the creatinine concentration decreased from $1.2 \mathrm{mg} / \mathrm{dl}$ to $0.79 \mathrm{mg} / \mathrm{dl}$, the lactate level returned to normal, and the pulmonary edema subsided. After 6 days the patient's condition improved sufficiently, and the off-pump (i.e. with Impella CP support) CABG was performed with LIMA-LAD anastomosis. During cardiac surgery, the position of the Impella was monitored by transesophageal echocardiography (Figure 1D; Supplementary material, Video S1).

The next day, the native cardiac output improved: CO, $2.7 \mathrm{I} / \mathrm{min}$ and CPO, $0.6 \mathrm{~W}$ (off 

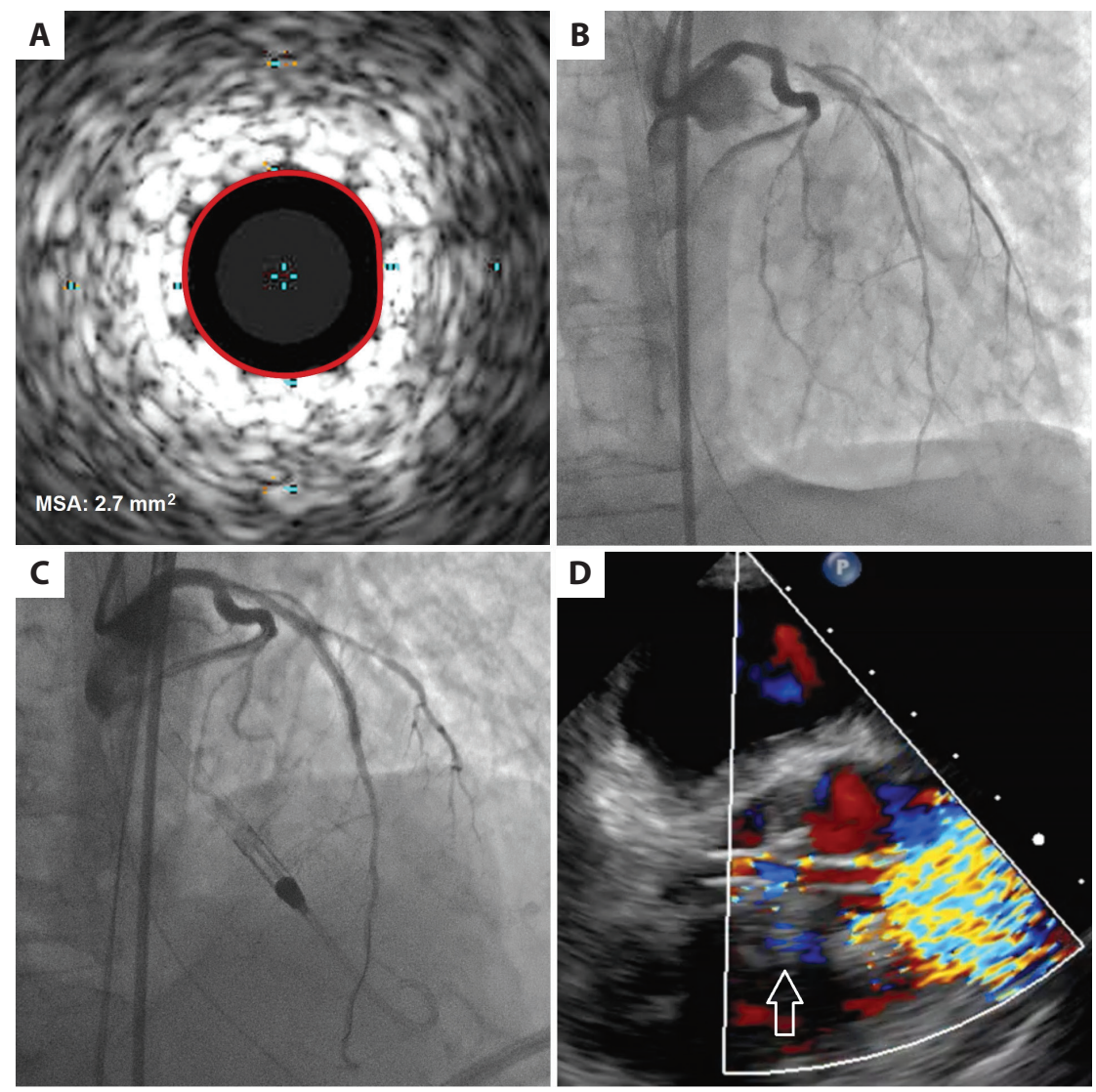

Figure 1. Impella CP during revascularization in cardiogenic shock. A. Intravascular ultrasound image shows 2 layers of under-expanded stents within the calcified circular lesion in the left anterior descending artery (LAD); the minimal stent area (MSA) is $2.7 \mathrm{~mm}^{2}$. B. Left coronary angiography presents critical thrombotic lesions in the LAD and distal chronic occlusion of the circumflex artery. C. Effect of the balloon angioplasty of the LAD with the Impella support. D. Transesophageal echocardiography during cardiac surgery shows a proper position of the Impella pump (see Supplementary material, Video S1): the biggest colored "storm" (i.e. the blood flow from the outlet) is above the aortic valve (the arrow indicates aortic cusps)

Impella) with no catecholamines infusion, and the Impella was removed. The access site was closed with two Proglide sutures, which were placed before the Impella insertion. After 2 weeks, the patient was transferred to the rehabilitation center.

Several reports indicate that the Impella 5.0 may assist CABG $[3,4]$, but there is only one report on the Impella CP in off-pump CABG [5]. Our case shows that in cardiogenic shock during $\mathrm{Ml}$, the Impella $\mathrm{CP}$ can support the entire treatment, i.e. both primary percutaneous coronary intervention, hemodynamic and metabolic stabilization, as well as off-pump CABG.

\section{Supplementary material}

Supplementary material is available at https://journals. viamedica.pl/kardiologia_polska.

\section{Article information}

Conflict of interest: None declared.

Open access: This article is available in open access under Creative Common Attribution-Non-Commercial-No Derivatives 4.0 International (CC BY-NC-ND 4.0) license, allowing to download articles and share them with others as long as they credit the authors and the publisher, but without permission to change them in any way or use them commercially. For commercial use, please contact the journal office at kardiologiapolska@ptkardio.pl.

How to cite: Sacha J, Kaperczak J, Gwóźdź W, et al. Impella CP in cardiogenic shock due to acute myocardial infarction: From primary angioplasty to LIMA-LAD grafting. Kardiol Pol. 2021; 79(12): 1389-1390, doi: 10.33963/KP.a2021.0152.

\section{REFERENCES}

1. Marin F, Pighi M, Pesarini G, et al. Devices for mechanical circulatory support and strategies for their management in cardiogenic shock. Kardiol Pol. 2019; 77(6): 589-595, doi: 10.33963/KP.14831, indexed in Pubmed: 31095122.

2. Baran DA, Grines $\mathrm{CL}$, Bailey S, et al. SCAI clinical expert consensus statement on the classification of cardiogenic shock: this document was endorsed by the American College of Cardiology (ACC), the American Heart Association (AHA), the Society of Critical Care Medicine (SCCM), and the Society of Thoracic Surgeons (STS) in April 2019. Catheter Cardiovasc Interv. 2019; 94(1): 29-37, doi: 10.1002/ccd.28329, indexed in Pubmed: 31104355.

3. Akay MH, Frazier OH. Impella Recover 5.0 assisted coronary artery bypass grafting. J Card Surg. 2010; 25(5): 606-607, doi: 10.1111/j.15408191.2010.01071.x, indexed in Pubmed: 20662974.

4. Pepino P, Coronella G, Oliviero P, et al. Successful use of the Impella Recover LP 5.0 device for circulatory support during off-pump coronary artery bypass grafting. Int J Surg Case Rep. 2014; 5(11): 803-805, doi: 10.1016/j. ijscr.2014.07.013, indexed in Pubmed: 25305600.

5. Upadhyaya VD, Campbell S, Douedi S, et al. Use of Impella CP device in off-pump coronary artery bypass graft surgery. Int Heart J. 2021; 62(1): 175-177, doi: 10.1536/ihj.20-482, indexed in Pubmed: 33455991. 